\title{
Planning Competency in the New Normal- Employability Competency in Post- COVID-19 \\ Pandemic
}

\author{
Mohamed Buheji \\ International Inspiration Economy Project- Bahrain \\ E-mail: buhejim@gmail.com
}

Aisha Buheji

Researcher - Bahrain

E-mail: aisha.buheji1@gmail.com

Received: May 5, 2020 Accepted: May 20, 2020 Online published: May 25, 2020

doi:10.5296/ijhrs.v10i2.17085 URL: https://doi.org/10.5296/ijhrs.v10i2.17085

\begin{abstract}
This paper explores requirements of employability competency in the new normal; an era expected post- the COVID-19 pandemic. The research conceptualises and integrates approaches that would address how to prepare individuals for times of uncertainties, changes and challenges they most probably would face during the new normal.

A framework for employability competency during new normal is proposed, followed by a toolkit that ensures we stay resilient to meet the variety of demands and the conditions expected during significant transformation times. This work opens a new line of research for empirical research that would support employability and competency development planners in the coming decades.
\end{abstract}

Keywords: COVID-19, new normal, competency, employability competency, resilient communities, planning competency

\section{Introduction}

Since the early days of 2020, the world has seen a series of incredible paradigm shifts in approximately every line of business, from huge increases in demand in some industries to total loss of demand in others. The world and the different generations are getting used to 
working from home or managing to deliver products or businesses remotely. This huge radical shift shows that the future will be different, and we need to prepare ourselves to another different era that needs a new paradigm and most importantly, different competency. Buheji (2020a), OECD (2019).

This research paper explores and foresight the competency and the employability competency required for the post-COVID-19 era, called the 'new normal'. It is an era full of challenges and instability, where agility, curiosity, risk mitigation, learning by exploring, learning by doing, but with focus, would be the norm for both survival and competitiveness. Levenson, (2020).

The researchers try to design the new competency requirements, with focus on the importance of 'inquiry-based learning' since it addresses many of the 'new normal' requirement, i.e. curiosity, learning by exploring, etc.

The literature review will explore the concepts of competency in times of change and the employability competency in a large complexity world where the rapid technological advancements and the huge economic problems that are occurring are all indicating the need for change now.

The type and strength of competency in the new normal, due to the learning from the COVID-19 crisis, would be much higher. The competency perceived for any employee or even self-employed entrepreneur would be agile and keep changing, as if we need to program ourselves as per the conditions of the community emergency or stability status. McArdle et al. (2007).

Thus, if this competency mismatch is not solved, it would create a crisis. The chances of unemployment among the post-COVID-19 generation is expected to be twice as the pre-COVID-19 generation if not more; unless innovative solutions as resilient competency program are developed for the new normal, and its frequently turbulent market. Buheji (2020a. 2020c).

The literature review in this paper focuses first in setting the base for what is meant by employability competency and in the new normal. Then, the employability competency in the new normal is assessed, followed by exploration for the type of challenges of employability during the new normal. The challenges expected for the education and training institutes are explored, then the two-dimensional framework would be proposed to address the needs of employability competency in the new normal. Levenson (2020), Hillage and Pollard (1998).

\section{Literature Review}

\subsection{Defining Employability Competency}

Employability can be defined as the individual's (perceived) ability to obtain and maintain employment throughout their career, Cole and Tibby (2013). According to Yorke (2006), the individual's employability is 'a set of achievements - skills, understandings and personal attributes - that makes graduates more likely to gain employment and be successful in their 
chosen occupations, which benefits themselves, the workforce, the community and the economy'. All these competencies variables are controlled by attitudes; thus, it should be taken into consideration as it dominates the mindset of the employee. Therefore, competency is a combination of: knowledge (formal and informal education, training, and experience), skills (practical usage of knowledge) and attitudes (like honesty, loyalty and the styles of action: a perfectionism and independence).

Attitudes are an essential part of competency, especially during conditions of a sudden change of environment, as the COVID-19, where the working environment would reshaping itself constantly, and uncertainty would be the norm. Thus, the educational institutions have a huge role to play to the creation of the employability competency attitudes that fits this uncertainty environment. Positive attitudes as proactiveness and preparedness would be highly expected attitudes of any labour market contender to show the readiness for the new normal.

Employability competency can be considered as the generic competency, generic capabilities, key competencies, core competency, key competency, common competency, essential competency, necessary skill, workplace competency, know-how competency, critical enabling competency, transferable competency, trans-disciplinary goals, key qualifications, independent process qualifications and emotional competency. George (2011).

Employability is a very important concept for policymakers and scholars as it focuses on preparing individuals and even communities for jobs that do not exist yet and even for solving problems and challenges that cannot be realised so far. Peeters et al. (2019) and Römgens et al. (2019).

The term employability competency in the new normal goes beyond the ability to obtain a job towards more the ability to maintain that job as well in difficult, challenging times, managing the challenges of the job in turbulent times. There are two main facets of employability that educational and training institutes in the new normal need to take into account: the ability of graduates to get a job and the ability of graduates to tackle the level of work that is being equipped for the job. Levenson (2020).

The socio-economic reality would emphasis more new approaches that ensure the integration of both educational and social inputs that would shape the competency. Thus, it is highly expected that the collection of education, skills, training and experience would be redefined.

Skill is defined as the ability to perform a specific task (DEST, 2006). While employability is about having the capacity to gain initial employment, maintain employment and obtain new employment if required (Hillage \& Pollard, 1998). This also covers self-employment.

Competency is made from a two-dimensional competence, conceptual and operational. This includes knowledge and understanding, applied psycho-motor skills, behaviour and attitudes and the ability to learn how to learn, as mentioned by (Delamare Le Deist and Winterton 2005).

The approaches that are driven by competence also see employability as a multi-dimensional 
process which develops over time. The obtaining and holding on for such competencies help to both obtain and retain the most suitable job, during highly competitive times in the labour market. Cole and Tibby (2013); Forrier and Sels (2003); Van der Heijde and Van der Heijden (2006).

Thus, employability competency can be seen as a set of achievements that develop the individuals' competency, enhance their understandings and personal attributes and make them more likely to gain employment and be successful in their chosen occupations, which benefit themselves, the workforce, the community and the economy. Clarke (2008).

\subsection{Defining the New Normal}

Oxford dictionary (2020) defines the new normal as an event, or status, or era that previously was unfamiliar, or atypical situation that has become standard, or usual, or expected.

A covid-19 pandemic is a sudden event, but this new normal can also be a consequence of broader changes in the modern world (like climate changes, migration, wars, poverty, hunger); besides the development of the technology. For this reason, the new post-pandemic reality, the new normal, is going to be a result of all mentioned changes. However, the attitudes and behaviours we had to follow during COVID-19 pandemic have shaped our life, in a few months, like no decade before in recent history. With the strive of the countries and the communities for effective containment of this contagious disease, the world is experiencing a huge disruption to all the economic activities and social life. The radical changes that people had to do due to management of risks; i.e. the need to react, to abide by the new regulations and to be prepared for the worst; have shacked-up the basis of many assumed concepts of life. Even now, we changed how we perceive doing business and deliver services in the future. Buheji (2020b), OECD (2019).

Since this pandemic might have a series of outbreaks, it is expected to have different phases where we need to react, then realise and reflect on the essence of the sudden major life challenges. As the world would strive to resume its activity towards the better productivity and progressive growth, it would need to go through fuzziness and would need to reshape itself to fit the pre-requisites of the next new normal. Levenson (2020), Helyer and Lee (2014).

The coming of next horizons of the post-COVID-19 era could be characterised as the 'urgency of the moment' era. Thus, the competency here is about the capacity of not losing sight of the actions that might be needed for tomorrow. Buheji and Ahmed (2019).

The new normal comes to ensure the community and organisations rapid response and the efficient adaptation to change. This would ensure that the world would be more ready for its re-emergence with a stronger position after each shock, or crisis or global challenge. Politico Magazine (2020).

Buheji (2020a) mentioned that the 'next normal' or the post-COVID-19 era would not be similar to the pre-COVID-19 years. The pandemic would touch the main issues of life, what we believe in, how we think, how we visualise our role in life, our next generation essentials, 
how we would react to a coming life crisis. Therefore, we need a new way of establishing and managing employability competency to meet this challenging era. Levenson (2020).

Meister (2020) noted that in the new normal, we would witness changes in the speed and quality of training for remote workers. The organisations would have as part of their package, the care for the worker future wellbeing, in return to high employability competency demand. Almost all leading organisations would work on re-skilling its employees, or recruit according to the new normal requirements.

\subsection{Assessing the Employability Competency in the New Normal}

This literature review signals the urge for employability competency and identifies some of the frameworks that can be adopted on the international level. Römgens et al. (2019) see that employability is a dynamic concept, constantly evolving and linked to the ability to learn from experiences. Robinson and Garton (2009).

Employability, in its simplest forms, means the ability to get a job and remain in that job. The competency shortage has been signalled in many studies notifying that there is a gap between the output of the educational and human development systems and what the industry in the new normal demands. Employability is highly linked to workplace learning; thus, it can be seen as the continuous fulfilling, acquiring or creating work through the optimal use of competences. Van der Heijde and Van der Heijden (2006).

Due to the transformation conditions in the new normal, organisations and communities need to work on counting on dynamic careers in which people need to take responsibility for self-managing the transitions in positions, or affiliation with multiple organisations and sectors. Such a dynamic condition and environment require the workers to manage change continuously.

Hence, organisations need to be more responsible for creating employability competency, whether before recruitment or after recruitment. The organisation in the new normal would be more involved in shaping the outcome of special processes as education and training in collaboration with the concerned educational and training institutes (ETIs) utilising the technology and conferencing facilities, as zoom and similar e-conferencing apps.

Due to the affordable cost of managing the employees productivity as the technology has proven during the pandemic, more strategic approaches in shaping the human resources competency within the organisation would be expected in the new norm. Römgens et al. (2019), Thijssen et al. (2008).

Due to the huge role of the higher education sector in the new normal economy, employability competency is expected to be the top agenda of any country planning to be stronger and more competitive in the new normal. Producing knowledgeable graduates with good academic standards will not be the top target, rather the top target would be focused on competitive graduates that would manage to overcome sudden and expected challenges and turn them to be a source of development and differentiation. Levenson (2020).

The concept of employability competency is not new, but students, especially generations- 
Alpha and Z, became more aware of attaining these competencies, Buheji (2020a) and DEST (2006). However, with the new normal, the academic competency will not be not considered enough as the employers in today's world. The employers would need more dynamic agile competencies that maybe academic education has helped to establish the seeds.

Employability competency would emerge in the next few years, after the provision of vaccination to the COVID-19, since the competency shortage would be a problem which would be signalled in many studies indicating a gap between the output of the educational systems and what the industry demands. Despite the fact that changes are occurring to different sectors in the economy, there were some common set of competencies desired in the new normal. Thus, the level at which employability competency impact the targeted students should be to the extent that it would affect our "subconscious mind".

\subsection{Understanding the Challenges of Employability During New Normal}

Römgens et al. (2019) see that employability can be defined as a multi-dimensional, competence-based construct in the fields of both pieces of research on higher education and workplace learning. However, the employability in the new normal can go further more than the actual attainment of the competency for the job, but rather the ability to focus on grasping the job itself. Fugate et al. (2004).

The ability to get a job is not affected by what credentials or certificates one carries anymore, but rather by the competency or collection of competencies that make their way in these challenging times.

Employability according to DEST (2002) is seen as competency required not only to gain employment, but also to progress within an enterprise so as to achieve one's potential and contribute successfully to enterprise strategic directions. Therefore, what is meant by employability in this paper should prepare graduates to join the society as citizens suitable to meet the demands of the new normal. Forrier and Sels (2003).

In order to measure employability, general recognition of the need of the new normal as per the demand of community, organisation or condition would need to be embedded, Harvey (2001). Therefore, measuring knowledge could be discrete facts, but measuring competency and abilities to apply knowledge in ambiguous circumstances is what can make the difference in a post-COVID-19 pandemic era. Clarke (2008).

\subsection{Challenges in New Normal Education and Training}

Due to the high unemployment that is expected in the new normal, there would be a series of challenges on both the educational and training institutions (ETIs) to clarify their total programs and journey towards employability. ETIs are expected to identify the set of competencies that they target their graduates to possess, as per the cluster, or the competitiveness of the community or the country and its condition, or phase during the new normal. ETIs then could adopt those employability competencies as they are or add some that are reflecting their own identity. The other challenge would be how to integrate learning program with a very dynamic, repeatedly changing world market and community conditions 
i.e. how to develop employability competency-driven courses and set it within the day to day teaching. Forrier and Sels (2003).

The other challenge would be the difficulty of contact with the industry as the industry would be busy with mitigating risks towards restabilising its position or fighting for its survival. However, if the contact with industry can be optimised through the arrangement of e-learning meetings with different industry leaders, this can compensate for the gap.

The perceptions of employability competency development, in the new normal, could differ across countries depending on their socio-economic conditions. Even the education system, the backbone of this competency development, which might be considered to be of good quality in one country is not necessarily perceived as such in another country. Buheji (2020b), Forrier and Sels (2003).

\subsection{Challenge of New Normal Skills and Experience}

Experience requires domain-specific knowledge, besides understanding the capability of specific skills. The skills can be generic or discipline or context-based. Regardless of which skills required, in a turbulent, fuzzy and non-predictive environment, the main competencies would need to be around imagination, curiosity, creativity, and resilience. Individuals with transferable generic skills would be of preference to recruit. Buheji (2020c), Helyer and Lee (2014).

Since many of the organisations are out of staff reserves in the new normal, and in turn, they are not able to get important competences in a short time; the organisational role and expectation of skills and experience would be very dynamic and would constantly be changing.

\section{Proposed Two-Dimensional Framework}

\subsection{Introduction to the Background of the Framework}

In order to meet the disruptive, fuzzy and turbulent 'new normal' demands of the employability competency, a two-dimensional framework is proposed. When we set a framework, we target to absorb and compensate for the turbulent dynamic era to come. The first-dimension focuses on the demands of the new normal that would be needed to control the competency exploitation. While the second-dimension focuses on the type of essential competencies required in the 'new normal'. The two dimensions complement each other to create the necessary resilient framework and make the competency employability like an elastic, resilient system that can absorb the shocks and bounce back. Buheji (2020c), Hillage and Pollard (1998).

The idea here is to mitigate and eliminate the risks of missing any important competency that might be needed in the new normal era as the education, training, skills and experience which for short referred to here as (ETSE). Helyer and Lee (2014) and George (2011).

\subsection{Dimension of $5 R s$}

This first dimension focuses on the demands of the new normal and its frequently repeated 
phases, or trends, where people to be competent and employable, are required to react, realise, resolve, reshape and be resilient. One could call this approach the 5Rs. Harvey (2001).

Thus, in order to meet the demands of the new normal, we are expected to 'react' with reliability. This means we need to ensure that all the activities delivered are safe and do not lead to further problems, thus ensure that all the different scenarios are taken into account. In order also to meet the demands of the 'realising' phase, we need to put concepts into reality. For example, through specifying what and where the challenges are, our realisation would improve. Then comes the 'resolve' phase, which targets to create communities back to being healthy and profitable. This would help to prepare the communities to reach the 'resilience' required to have the tolerance required for the effective transformation of a new flourishing era. Buheji (2020c).

\subsection{Dimension of $5 P S$}

The employability competencies required are summarised as the 5Ps, represented by the proactiveness, preparedness, pulling-together, problem-solving, followed by the last constraint as publishing and publicising. The 'proactiveness competency' contributes to the capacity to prepare ahead to-, or to deal with- an expected challenge or foresighted possibility, Buheji and Ahmed (2020). While the 'preparedness competency' focuses on the quality or the state of being always prepared to different sort of emergencies. Since teamwork needs to be agile, the third $\mathrm{P}$ is represented by 'pull-together' competency. This competency represents the capacity to process and exchange information between individuals through a common system, or a behaviour that creates a productive and harmonious environment.

The fourth employability competency focus on the problem-solving. This competency could be seen in the capacity of the individual in finding the most effective and maybe the most efficient solutions to difficult or complex issues or challenging conditions. The last competency focuses on the importance of publishing and publicising the work as soon as possible in order to share necessary information or knowledge that would help humanity to overcome certain new normal phase. This competency helps to show ongoing self-improvement and sharing developments.

\subsection{Visualisation of How the Framework Works}

Based on the rhythm of the new normal, the working environment expects from all to be proactive, prepared, and to able to work with people closely (not only in the team, but with close spirit). Besides, we are expected more than ever to solve problems and share the knowledge instantly, i.e. publish whatever learned, so that others learn and benefit from and avoid repeating the same mistakes. This means we need to build up the main pre-requisites for such new normal environment where we would be able to react, realise, resolve, reshape and be more resilient.

Figure (1) shows a visualisation of how the gaps in ETSE would be colour coded to represent a codification and classification of the level of competency achieved. The colours can be according to the employers' desire, or the demands of the market condition. The circle represents the fitness of the competency required for the employability and what gauges the 
level of shortages.

These employability competency constructs set the necessary behaviours which contribute to the overall interchangeably to suit the specific industry needs. Fugate et al. (2004) and Hillage and Pollard (1998).

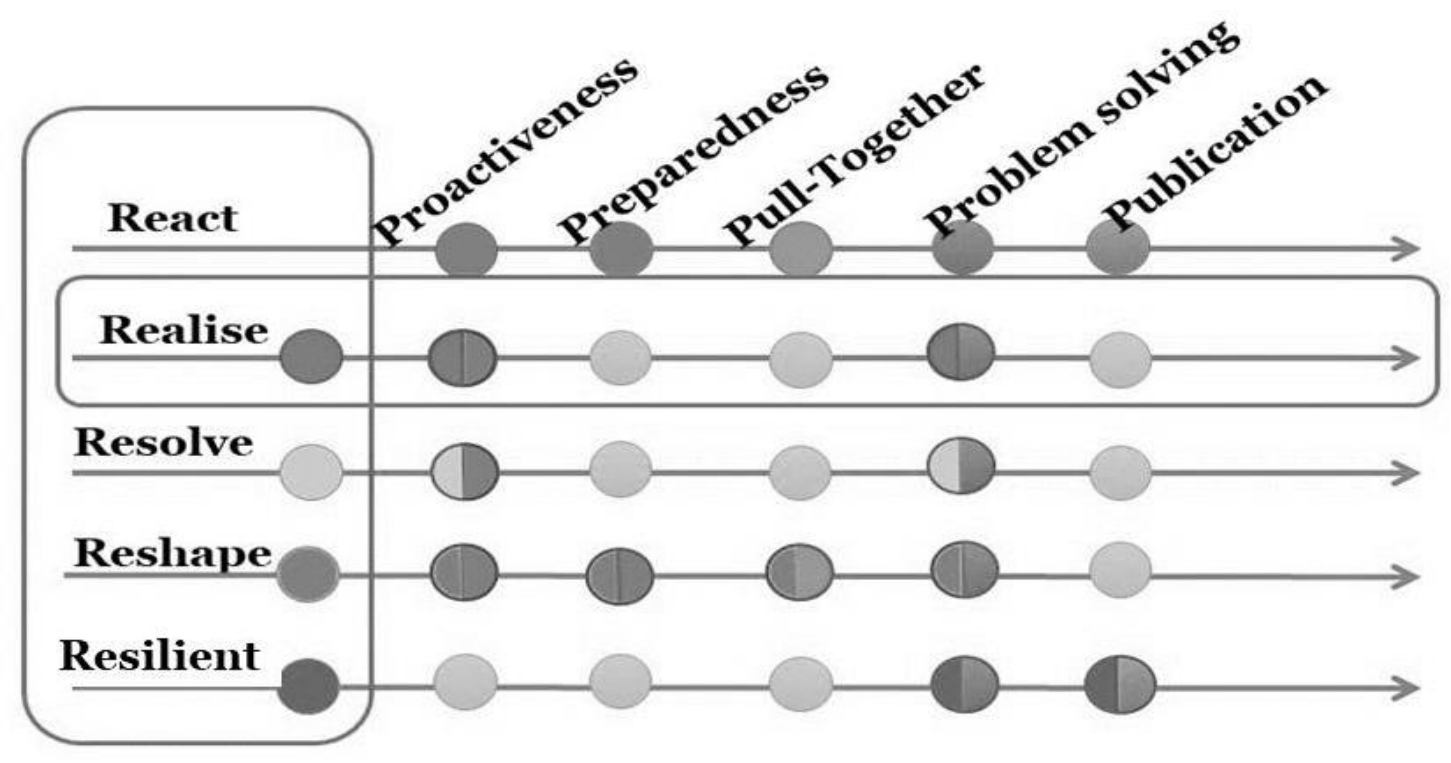

Figure (1). Illustrates the New Normal 2-D Employability Competency Framework

\section{Methodology}

Based on the literature review and the synthesis that led to the proposed framework a table representing the toolkit for the implementation of the proposed 'new normal employability competency scale' is designed to help manage the conditions of the era. The purpose of the table is to link between the 2-D framework, the conditions of the new normal, the four-competency set (ETSE) and the extra speciality requirements, i.e. depending on the profession, the job or the process assigned.

A scenario of detailed implementation would help to draw both discussion and conclusion in order to help to encourage further research in the area and generalise a model that suits the dynamics frequencies coming in the next era.

\section{Application of New Normal 'Comprehensive Employability Competency' Toolkit}

The following Table (1) was developed as a toolkit for implementing the competency framework of the new normal. The table sets an opportunity for designing the 'most suitable employability competency program' in a post-pandemic environment, be it for educational institute, or human capital department, or even government planners as the ministry of education. Table (1) links the condition that we might face during the new normal or transformation stage during and after an emergency situation as the COVID-19 pandemic with the 2-D employability competency framework, i.e. the 5Rs and 5Ps. Then, link the core 
competency constructs the ETSE with the previous new normal group, shaded in grey, besides the specific or extra speciality requirements.

Table (1). Toolkit for Planning' Employability Competency Program' for the New Normal

\begin{tabular}{|l|l|l|l|l|l|}
\hline Condition & 5Rs & 5Ps & $\begin{array}{l}\text { Education } \\
\text { \& Training }\end{array}$ & $\begin{array}{l}\text { Skills \& } \\
\text { Experience }\end{array}$ & $\begin{array}{l}\text { Extra } \\
\text { Speciality } \\
\text { Requirements }\end{array}$ \\
\hline Stable & React & Proactive & $\ldots$. & $\ldots$. & $\ldots$. \\
\hline Unstable & Realise & Prepared & $\ldots$. & $\ldots$. & $\ldots$. \\
\hline $\begin{array}{l}\text { Lockdown } \\
\text { Emergency }\end{array}$ & Resolve & $\begin{array}{l}\text { Pulling } \\
\text { Together }\end{array}$ & $\ldots$. & $\ldots$. & $\ldots$. \\
\hline Fuzzy & Reshape & $\begin{array}{l}\text { Problem } \\
\text { Solver }\end{array}$ & $\ldots$. & $\ldots$. & $\ldots .$. \\
\hline $\begin{array}{l}\text { Progressive } \\
\text { Growth }\end{array}$ & Resilient & $\begin{array}{l}\text { Publishing } \\
\text { \& } \\
\text { Publicising }\end{array}$ & $\ldots$. & $\ldots$. & $\ldots$. \\
\hline
\end{tabular}

Further implementation of this framework field tool is given in Figure (2). The figure shows the 'employability competency planning program' (ECPP) toolkit during the new normal, where the planner can draw the basis for the plan on the table. For example, and as given herein Figure (2) if the condition of the country due to the virus outbreak or due to a global emergency of COVID-19 pandemic stays in lockdown, then we need to link it to specific competency that is targeted in the individual, or the group, whether it is being available, or need to be acquired.

The arrow in Figure (2) represents the flow of employability competency required, while the circle represents what needs to be filled by the employability competency planner. The dotted circle represents the need for a type of a 'mentorship support', or 'learning by doing' during the early stages of the recruitment. Thus, the mapping on the toolkit represents the whole story or say the whole journey expected to have a person have the exact fitness for the purpose, in a very turbulent era as the new normal.

To show the full illustration in this paper, let us imagine that we were to employ a physician for the national emergency call centre during the crisis. The first thing, in this case, we need this physician to be competent enough to realise and accept the situation and tries to be a competent problem solver. Then, if we decide that we need the targeted physician to have ET1, given here for illustration to be having engineering mindset with medical education.

If this is successful, then the planner needs to design for this physician the specific training needs, which is here as an example would be a two weeks crash course on the 'continuity of enterprise communication during the emergencies, or the disasters'. Then, we need to decide which type of skills and experience would be most suitable. Let us say we choose SE3 to be the most suitable as it represents skills in 'emotional intelligence' and a minimum of four years in 'managing teams'. If we found that the physician needs support in managing team, the organisation can put a partner to mentor the teams and help facilitate them, in support of 
the physician.

Finally, the 'employability competency planner' might need to modify, or align, or calibrate a specific profession to a specific assignment during or after the pandemic, or as we start the transformation to the new normal. Here, we can optimise the physician capacity for the ESR1, taken here to be a profound knowledge in occupational health and safety, along with the ESR5, which is a capacity for dealing with emergency calls, handling 'difficult people' or 'critical situations'.

Figure (2) Illustrates the Example of the ECPP Toolkit Linking Competency with Employability required in the New Normal

\begin{tabular}{|c|c|c|c|c|c|}
\hline Condition & 5Rs & 5Ps & $\begin{array}{l}\text { Education \& } \\
\text { Training }\end{array}$ & \begin{tabular}{|l|} 
Skills \& \\
Experience
\end{tabular} & $\begin{array}{l}\text { Extra Speciality } \\
\text { Requirements } \\
\text { - v }\end{array}$ \\
\hline Stable & React & Proactive & ET1 & SE1 & Étis \\
\hline Unstable & Realise & Prepared & ET2 & SE2 & ESR2 \\
\hline $\begin{array}{l}\text { Lockdown } \\
\text { /Emergency }\end{array}$ & Resolve & $\begin{array}{l}\text { Pulling } \\
\text { Together }\end{array}$ & ET3 & & ESR3 \\
\hline Fuzzy & Reshape & $\begin{array}{l}\text { Problem } \\
\text { Solver }\end{array}$ & ET4 & $\mathrm{SE}_{4}$ & ESR4 \\
\hline $\begin{array}{l}\text { Progressive } \\
\text { Socio- } \\
\text { Economic } \\
\text { Growth }\end{array}$ & Resilient & $\begin{array}{l}\text { Publishing \& } \\
\text { Publicising }\end{array}$ & $\mathrm{ET}_{5}$ & $\mathrm{SE} 5$ & ESR5, \\
\hline
\end{tabular}

Represents the Flow of Employability Competency Required

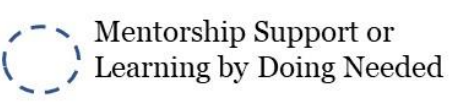

Needs to filled by the

Employability Competency

Planner

\section{Discussion and Conclusion}

\subsection{Value of this Research for Future Employability Competency}

This research showcases the employability competency that could help to overcome the challenges in the new normal.

The framework proposed focuses on addressing the requirements of the new normal, the basic competency to manage the minimal requirements of any job during these challenging times. Although the realisation for the need of employability competency is not new, the employability problem in the new normal would need to be resolved by innovative radical and dynamic approaches to prevent further unemployment. Cole and Tibby (2013).

The researchers call upon doing more research on what barriers would be facing the employers, or would be the demands of the future's market, so that more seeds and mechanism of competencies can be developed in the right time. Specifically, this is more important now as many of the proposed employability competencies depend on the 
engagements and the involvement of the individual and readiness of his mindset. This means many national strategies need to be changed to fit this foresighted new normal requirement so that more development opportunities be discovered. Buheji and Ahmed (2020).

\subsection{Implications of This Research}

This research can form a source motivation for national employability and competency planners, educational leaders, human capital and human resources facilitators, department of labour experts and government economists, so that they choose the appropriate development teaching and coaching methods that can have an impact on having the country or the community ready for the new normal competency demands.

Besides higher educational and training institutes, many organisations could benefit from this paper as they prepare to meet the requirements of the new normal. One could also expect that the demand for new employability competency with shape a new type of organisations in the future. However, further research needs to be cover in this area.

The paper presents one of their main complexities associated with the new normal, that is building individuals and communities competency that would be considered to be unique and valuable. The researchers managed to expose the need for different competencies that depends on complex hybrid requirements, as shown in toolkit proposed. This means different curriculum, teaching and training techniques need to be prepared before even the end of a global pandemic, similar to the COVID-19. The framework and the toolkit offer a good opportunity to think positively about the crisis of the COVID-19 and direct spending on preparing non-perishable assets, that is the human capital that could be prepared more for future crisis.

\subsection{Final Words}

Due to this paper being written at the early stages of the pandemic, it carries one main limitation in that it is not empirically tested. However, this work lays the profound basis for personal development practices in the new normal which would contribute to bringing in a generation that would fit the conditions of the era and continuously be resilient to meeting its demands.

The world seriously needs more work on this area, if we are to see mitigation of the sharply increasing unemployment due to the COVID-19 pandemic. The reliability of the framework proposed is its simplicity and its adaptability to being modified and implemented in any country or community regardless of its socio-economic status, or emergency condition. The researchers sincerely hope that the paper provides more insights about the new roles and dynamics of the competencies required for the next critical milestones of our human civilisation and journey. Buheji (2020b).

\section{Reference}

Buheji, M. (2020a). Future Foresight of Post COVID-19 Generations. International Journal of Youth Economy, 4(1), I-III. https://doi.org/10.18576/ijye/040101 
Buheji, M. (2020b). Socio-Economic Projects Spillovers and Their Influence on Communities Development. Review of European Studies, 12(1), 47-54. https://doi.org/10.5539/res.v12n1p47

Buheji, M. (2020c). Visualising Resilient Communities, Authorhouse Publishing, UK.

Buheji, M., \& Ahmed, D. (2020) Foresight of Coronavirus (COVID-19) Opportunities for a Better World. American Journal of Economics, 10(2), 97-108.

Clarke, M. (2008) Understanding and Managing Employability in Changing Career Contexts. Journal of European Industrial Training, 32(4), 258-284. https://doi.org/10.1108/03090590810871379

Cole, D., \& Tibby, M. (2013) Defining and Developing Your Approach to Employability. York: The Higher Education Academy.

Delamare Le Deist, F., \& Winterton, J. (2005) What is Competence? Human Resource Development International, 8(1), 27-46. https://doi.org/10.1080/1367886042000338227

DEST (2006). Employability Competency from Framework to Practice. A report by the Australian Chamber of Commerce and Industry and the Business Council of Australia for the Department of Education, Science and Training. http://www.velgtraining.com/library/files/Employability\%20Competency\%20From\%20Fram ework $\% 20$ to $\% 20$ Practice $\% 20 \% 20$ An $\% 20$ introductory $\% 20$ Guide $\% 20$ for $\% 20$ Trainers $\% 20$ and $\% 20$ Assessors.pdf Accessed on: 20/4/2020

DEST. (2002) Employability competency for the future. Department of Education, Science and Training. http://www.voced.edu.au/content/ngv\%3A12484

Forrier, A., \& Sels, L. (2003). The Concept Employability: A Complex Mosaic. International Journal of Human Resources Development and Management, 3(2), 103-124. https://doi.org/10.1504/IJHRDM.2003.002414

Fugate, M., Kinicki, J., \& Ashforth, B. (2004) Employability: A Psycho-Social Construct, its Dimensions, and Applications. Journal of Vocational Behavior, 65, 14-38. https://doi.org/10.1016/j.jvb.2003.10.005

George, R. (2011) Fostering Generic Skills through Participatory Learning Strategies. International Journal of Fundamental Psychology and Social Sciences, 1(1), 14-16. http://fundamentaljournals.org/ijfpss/downloads/4-Reena\%20George\%20N1\%20pp(14-16).p df Accessed on: 5/4/2020

Harvey, L. (2001) Defining and Measuring Employability. Quality in Higher Education, 7(2), 97-109. https://doi.org/10.1080/13538320120059990

Helyer, R., \& Lee, D. (2014). The Role of Work Experience in the Future Employability of Higher Education Graduates. Higher Education Quarterly, 68(3), 348-372. https://doi.org/10.1111/hequ.12055

Hillage, J., \& Pollard, E. (1998) Employability: Developing a Framework for Policy Analysis. 
London: DfEE.

Inge, R., Rémi, S., \& Simon, B. (2019) Unraveling the concept of employability, bringing together research on employability in higher education and the workplace, Studies in Higher Education.

Levenson, A. (2020). A Long Time Until the Economic New Normal, Leaders must learn from the pandemic now to position their companies to thrive in the next crisis. Sloan Review, MIT, April

10. https://sloanreview.mit.edu/article/a-long-time-until-the-economic-new-normal/

McArdle, S. L., Waters, J. P., Briscoe, \& Hall, D. T. (2007) Employability During Unemployment: Adaptability, Career Identity and Human and Social Capital. Journal of Vocational Behavior, 71, 247-264. https://doi.org/10.1016/j.jvb.2007.06.003

Meister, J. (2020). The Impact of The Coronavirus on HR and The New Normal of Work. Forbes.

March.

https://www.forbes.com/sites/jeannemeister/2020/03/31/the-impact-of-the-coronavirus-on-hrand-the-new-normal-of-work/\#178b9d232b60 Accessed on: 10/4/2020

OECD. (2019) THE FUTURE OF WORK, OECD Employment Outlook. https://www.oecd.org/employment/Employment-Outlook-2019-Highlight-EN.pdf Accessed on: $10 / 4 / 2020$

Oxford Dictionary. (2020). Meaning of the new normal in English. https://www.lexico.com/definition/the_new_normal Accessed on: 10/4/2020

Peeters, E. J., Nelissen, N., De Cuyper, A., Forrier, M., Verbruggen, \& De Witte, H. (2019) Employability Capital: A Conceptual Framework Tested Through Expert Analysis. Journal of Career Development, 46(2), 79-93. https://doi.org/10.1177/0894845317731865

Politico Magazine (2020) Coronavirus Will Change the World PermanentlyHere's's How. 19 March.

https://www.politico.com/news/magazine/2020/03/19/coronavirus-effect-economy-life-societ y-analysis-covid-135579 Accessed on: 10/4/2020

Robinson, J., \& Garton, B. (2009). An assessment of the employability skills needed by graduates. Journal of Agricultural Education, 49(4), 96-105. https://doi.org/10.5032/jae.2008.04096

Thijssen, J., Van der Heijden, J., \& Rocco, T. (2008) Toward the Employability-Link Model: Current Employment Transition to Future Employment Perspectives. Human Resource Development Review, 7(2), 165-183. https://doi.org/10.1177/1534484308314955

Van der Heijde, C., \& Van der Heijden, B. (2006) A Competence-based an Multi-dimensional Operationalisation on and Measurement of Employability. Human Resource Management, 45(3), 449-476. https://doi.org/10.1002/hrm.20119 


\section{Copyright Disclaimer}

Copyright for this article is retained by the author(s), with first publication rights granted to the journal.

This is an open-access article distributed under the terms and conditions of the Creative Commons Attribution license (http://creativecommons.org/licenses/by/4.0/). 